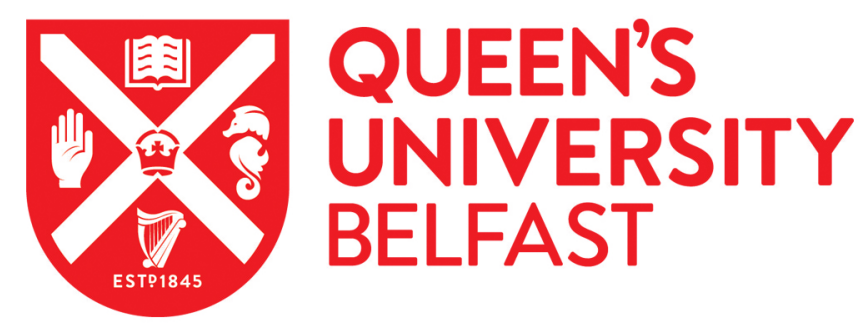

\title{
The obstacles to maximising the impact of public access defibrillation: an assessment of the dispatch mechanism for out-of-hospital cardiac
} arrest

Cairns, K., Hamilton, A. J., Marshall, A., Moore, M. J., Adgey, A. J., \& Kee, F. (2008). The obstacles to maximising the impact of public access defibrillation: an assessment of the dispatch mechanism for out-ofhospital cardiac arrest. Heart, 94(3), 349-353. https://doi.org/10.1136/hrt.2006.109785

Published in:

Heart

Queen's University Belfast - Research Portal:

Link to publication record in Queen's University Belfast Research Portal

\section{General rights}

Copyright for the publications made accessible via the Queen's University Belfast Research Portal is retained by the author(s) and / or other copyright owners and it is a condition of accessing these publications that users recognise and abide by the legal requirements associated with these rights.

Take down policy

The Research Portal is Queen's institutional repository that provides access to Queen's research output. Every effort has been made to ensure that content in the Research Portal does not infringe any person's rights, or applicable UK laws. If you discover content in the Research Portal that you believe breaches copyright or violates any law, please contact openaccess@qub.ac.uk. 


\title{
The obstacles to maximising the impact of public access defibrillation: an assessment of the dispatch mechanism for out-of-hospital cardiac arrest
}

\author{
K J Cairns, ${ }^{1}$ A J Hamilton, ${ }^{2}$ A H Marshall, ${ }^{1}$ M J Moore, ${ }^{2}$ A A J Adgey, ${ }^{2}$ F Kee ${ }^{3}$
}

${ }^{1}$ Centre for Statistical Science and Operational Research (CenSSOR), Sir David Bates Building, Queen's University Belfast, UK; ${ }^{2}$ Regional Medical Cardiology Centre, Royal Victoria Hospital, Belfast, UK; ${ }^{3}$ Centre for Clinical and Population Sciences, Queen's University Belfast, Belfast, UK

Correspondence to: Karen J Cairns, Statistician, Centre for Statistical Science and Operational Research (CenSSOR), Room 01.008, Sir David Bates Building, Queen's University Belfast, UK, BT7 1NN; k.cairns@qub.ac.uk

Accepted 27 February 2007 Published Online First 31 May 2007

\section{ABSTRACT}

Objectives: To determine the diagnostic accuracy of advanced medical priority dispatch system (AMPDS) software used to dispatch public access defibrillation first responders to out-of-hospital cardiac arrests (OHCA).

Design: All true OHCA events in North and West Belfast in 2004 were prospectively collated. This was achieved by a comprehensive search of all manually completed Patient Report Forms compiled by paramedics, together with autopsy reports, death certificates and medical records. The dispatch coding of all emergency calls by AMPDS software was also obtained for the same time period and region, and a comparison was made between these two datasets.

Setting: A single urban ambulance control centre in Northern Ireland.

Population: All 238 individuals with a presumed or actual OHCA in the North and West Belfast Health and Social Services Trust population of 138591 (2001 Census), as defined by the Utstein Criteria.

Main outcome measures: The accurate dispatch of an emergency ambulance to a true OHCA.

Results: The sensitivity of the dispatch mechanism for detecting OHCA was 68.9\% (115/167, 95\% confidence interval (Cl) $61.3 \%$ to $75.8 \%$ ). However, the sensitivity for arrests with ventricular fibrillation (VF) was $44.4 \%$ (12/27) with sensitivity for witnessed VF of $47.1 \%(8 / 17)$. The positive predictive value was $63.5 \%(115 / 181,95 \% \mathrm{Cl}$ $56.1 \%$ to $70.6 \%)$.

Conclusions: The sensitivity of this dispatch process for cardiac arrest is moderate and will constrain the effectiveness of Public Access Defibrillation (PAD) schemes which utilise it.

Trial registration: controlled-trials.com ISRCTN 07286796.

Although mortality from coronary heart disease has been falling for over 30 years, the reduction in deaths outside hospital from sudden cardiac arrest has not been as significant. ${ }^{1}$ Currently, only around $5 \%$ of individuals survive out-of-hospital cardiac arrest (OHCA). ${ }^{2}$ Much of this mortality is due to ventricular arrhythmias and the most important determinant of survival following OHCA is rapid defibrillation. Public access defibrillation (PAD) schemes aim to address this issue by widespread dissemination of automated external defibrillators (AEDs).

Evidence of the potential effectiveness of PAD schemes has come from observational trials in airlines and airports ${ }^{3}$ and in some communities employing police personnel, ${ }^{4}$ with survival rates for witnessed ventricular fibrillation of up to $50 \%$. A national PAD trial in the United States has shown encouraging results ${ }^{5}$ and evaluation of a national scheme in England and Wales is ongoing. ${ }^{6}$ This latter project has initially concentrated its defibrillators in fixed sites, placing over 2000 AEDs at large public transport intersections. Many areas, however, are also beginning to establish local mobile PAD "First Responder" schemes.

A feature of the literature in this field is that we seldom learn much from published accounts of successful PAD programmes about how local geography, first responder availability, and the dispatch mechanisms themselves have had a bearing on the design or outcome of the programme. It is obvious that these factors can be crucial to their success. In particular, for $\mathrm{PAD}$ schemes that rely mainly on mobile volunteers, the specificity of the dispatch mechanism (relating to whether responses are initiated for conditions other than OHCA), and its sensitivity (the proportion of OHCA for which a response is triggered) need to be considered as part of their design and evaluation.

The Northern Ireland Public Access Defibrillation (NIPAD) study is a "mixed-economy" PAD scheme using both mobile and fixed location AEDs. These were utilised by lay First Responders and volunteers from the Police Service of Northern Ireland, who delivered treatment with an AED at the scene of an OHCA. The scheme was deployed in an urban and rural area of Northern Ireland from January 2005 (Clinical trial number ISRCTN: 07286796). Data was prospectively collected on the incidence, demographic characteristics and survival rates of OHCA patients in two regions of Northern Ireland, in the year prior to the $\mathrm{PAD}$ scheme being implemented. Using this data, we obtained an indication of the effectiveness of the usual dispatch mechanism and the possible impact on a PAD scheme.

\section{METHODS}

The Northern Ireland Ambulance Service routinely records a computerised data set on all emergency 999 calls. These are automatically coded for their urgency and type, using advanced medical priority dispatch system ${ }^{7}$ (AMPDS) software v11.1. We evaluated the capability of this software to categorise actual OHCA events and thus ultimately assess the success of the NIPAD dispatch mechanism, which utilises it.

In the NIPAD study, PAD volunteers are notified of probable OHCA events during the course of an emergency 999 call, via alphanumeric pagers. When 
an emergency call is received, the call taker initially asks for confirmation of the telephone number and the address of the incident. The AMPDS system used by the Northern Ireland Ambulance Service then prompts the call taker by means of an on-screen message to ask three questions: "Tell me what the problem is?; Is the person completely awake or conscious?; Is the person breathing?". If the answers are negative to the latter two questions, a dispatch code of cardiac arrest is assigned. The computer system then automatically activates the local PAD pagers. While the call taker is receiving further information, a separate ambulance dispatcher contacts the nearest ambulance station, requests the next available crew to activate, and provides the address details. The crew is then updated with details of the medical condition. Meanwhile, the caller remains on the telephone line and telephone advice is given by the call taker which will include advice on Cardio-Pulmonary Resuscitation.

In order to assess the success of this dispatch mechanism, we obtained the AMPDS categorisation of a complete set of emergency events in 2004, together with a complete list of actual OHCA events that occurred within the same time period. This was in the North and West Belfast study area, where the AMPDS software was first implemented in Northern Ireland. It spans a geographical area of $60 \mathrm{~km}^{2}$, with a population of $138591 .^{8}$ The study area is primarily an urban residential area located on the river Lagan basin. It is served by a physician-led cardiac ambulance and paramedic led ambulances based at four stations. There is a single regional emergency dispatch centre located in the city.

The complete list of OHCA events was obtained by assessing information from several sources. One source was the Patient Report Form (PRF) completed by paramedics at the scene of the incident. This included whether the event was witnessed, the occurrence of bystander cardiopulmonary resuscitation, the rhythm on emergency medical service (EMS) arrival and survival, defined as admission to hospital alive. This provided valuable information on the details of the arrest and the subsequent management by the paramedic. The PRFs of all emergency calls from the four Belfast ambulance stations over this time period were examined on a weekly basis in order to ascertain possible OHCA events.

In addition, all autopsy reports of the Northern Ireland State Pathologist were searched, including all Coroners' cases for the year 2004. All cases that were obviously non-cardiac were excluded, including overdoses, suicides, smoke inhalation, trauma, asthma, those under the age of 11 and patients known to be dying of terminal cancer. OHCA was categorised according to the Utstein criteria. ${ }^{9} 10$

Independent assessments were made by three cardiologists in order to reach a consensus on whether each case met the criteria for sudden cardiac death. Unanimous agreement was typically reached for over $90 \%$ of the cases considered independently. For the remaining cases a re-examination of the data enabled a consensus to be reached.

Autopsies were included reporting cardiac pathology, which had been performed on victims for whom the EMS were not called but the victim had been seen alive and asymptomatic within 24 hours of being found collapsed. Autopsies were performed on cases of sudden death where the General Practitioner was uncertain of the cause of death. This accounted for $29 \%$ of all cases of OHCA. Death certificates with cardiac causes for patients to whom the EMS were not called and who had no post mortem were not included in the analysis, as previous work has shown that reliance on death certificate diagnosis alone overestimates the true rate of out of hospital cardiac arrest. ${ }^{11}$

We used data from North and West Belfast in 2004 to estimate the proportion of all OHCA events in the area that would have resulted in a PAD volunteer being notified. ${ }^{12}$ Furthermore, we examined the proportion of events that would have triggered a PAD response in the belief that the call related to an OHCA event, when this subsequently proved not to be the case. In order to fairly assess this proportion we re-examined all PRFs for those initially categorised as OHCA. Where this was incomplete, we utilised the information given to the dispatcher at the time of the call, in order to enable follow-up and thus judge whether those events coded as cardiac arrest at the time of dispatch could be plausible OHCA events. Thus we used name and address details provided at the time of dispatch, in order to search death certificates and medical records for additional information.

Ethics approval was granted for this research by the Office for Research Ethics Committees Northern Ireland (ORECNI) at Queen's University Belfast. Exact 95\% confidence intervals were calculated for binomial proportions.

\section{RESULTS}

During the study period of 2004, there were 181 calls given a dispatch code of cardiac arrest within North and West Belfast. Table 1 provides details on the number of these events that were subsequently determined to be OHCA events.

Of the 181 incidents, 106 were confirmed as OHCA events of a cardiac aetiology. Of the remaining 75 events, we verified that 52 events were of a non-cardiac nature through re-examination of data. For the 23 other events originally coded "Cardiac/ Respiratory Arrest /Death" at the time of dispatch, where the electronic PRF could not be retrieved, 14 were believed to be highly implausible and of a non-cardiac nature (according to the Utstein criteria), a conclusion based on the free text dispatch information. The remaining nine events could not be excluded as OHCA events because of the limited amount of reliable information gathered by the call taker at the time of dispatch.

Table 2 gives a breakdown of the field diagnoses for the 52 non-OHCA patients incorrectly given a code of "Cardiac Arrest" at the time of dispatch.

An upper estimate of the positive predictive value (PPV) for events categorised as cardiac arrest at the time of dispatch is thus $(106+9) / 181=63.5 \%$ (95\% CI: $56.1 \%$ to $70.6 \%$ ).

By performing a manual examination of the PRFs, together with autopsy reports, death certificates and medical records, an additional 57 OHCA events were found, which were not originally categorised at dispatch as being OHCA (see table 1). These additional OHCA events include a small number of events where the EMS was not alerted to attend. In North and West Belfast this appeared to have been a relatively infrequent occurrence with only 5/163 (3.1\%) confirmed OHCA events resulting in no EMS deployment.

The categorisation given by the EMS software at the time of dispatch was determined for the 52 events which received an EMS deployment but without an initial dispatch diagnosis of cardiac arrest. Table 3 provides a breakdown of the actual dispatch codes given to confirmed OHCA events, in descending order of use.

An upper estimate of the sensitivity of the dispatch mechanism in predicting cardiac arrest events is thus (106+9)/ $(163+9-5)=68.9 \%$ (95\% CI: $61.3 \%$ to $75.8 \%)$, assuming that the EMS has been deployed to the event. 
Table 1 Breakdown of the patient groups between those given a dispatch code of cardiac arrest at the time of the emergency call and/or those determined to be out-of-hospital cardiac arrest (OHCA) patients

\begin{tabular}{|c|c|c|c|c|c|c|}
\hline & & \multicolumn{4}{|c|}{ Determined cause of event } & \multirow{3}{*}{ Total } \\
\hline & & \multicolumn{2}{|c|}{$\begin{array}{l}\text { Verified by EMS patient report forms, } \\
\text { autopsy or medical records }\end{array}$} & \multirow{2}{*}{$\begin{array}{l}\text { Implausible OHCA event } \\
\text { given dispatch information }\end{array}$} & \multirow{2}{*}{$\begin{array}{l}\text { Plausible OHCA event given } \\
\text { dispatch information }\end{array}$} & \\
\hline & & OHCA & Non-OHCA & & & \\
\hline \multirow[t]{3}{*}{ Dispatch coding given } & Cardiac arrest & 106 & 52 & 14 & 9 & 181 \\
\hline & Other causes & 52 & & & & \\
\hline & Subtotal & 158 & & & & \\
\hline \multicolumn{2}{|l|}{ Total } & 163 & & & & \\
\hline
\end{tabular}

In total, there were 27 cases of Ventricular Fibrillation (VF) / Ventricular Tachycardia (VT) in the 2004 period, of which, 17 cases were witnessed cardiac arrests (see fig 1). Of the 27 cases of VF/VT, 12 were coded as presumed cardiac arrest. The other diagnoses were: seven cases of "unconscious/fainting", four cases of "chest pain", three cases of "breathing problems", and one case of "unknown problem - collapse 3rd party". Thus the sensitivity of the dispatch mechanism in detecting VF/VT was $44.4 \%(12 / 27)$ in North and West Belfast in 2004. Further analysis revealed that of the 17 witnessed arrests with VF/VT the dispatch code was "cardiac arrest" in only eight cases (47.1\%).

There were eight survivors of OHCA to hospital discharge, all of whom had VF/VT at presentation. Of these cases $7 / 8$ were witnessed and $5 / 8$ were coded as cardiac arrest.

For those confirmed OHCA cases that were coded as cardiac arrest at the time of dispatch, only 12/106 (11.3\%) were in VF/ VT. This suggests a somewhat pessimistic upper limit to the effectiveness of a PAD programme. This view should be tempered however as the proportion of cases diagnosed with VF will be increased by a shorter call to response interval. This was demonstrated in the treatment of cardiac arrests in the atypical environment of Las Vegas Casinos. ${ }^{13}{ }^{14}$

\section{DISCUSSION}

While the effectiveness of PAD has been established, some doubts have been cast on the cost-effectiveness of fixed site public access defibrillation, ${ }^{15}$ as over $80 \%$ of OHCAs occur in the patient's home. ${ }^{16}{ }^{17}$ The findings of several modelling studies ${ }^{18}$ and the evaluation of PAD in the Italian cities of Piacenza ${ }^{19}$ and Brescia $^{20}$ supply evidence that placing AEDs in the hands of a mobile volunteer may be critical to the success of a PAD

Table 2 Scene medical diagnosis for 52 non-OHCA patients inappropriately coded adult "Cardiac arrest" at time of dispatch

\begin{tabular}{lr}
\hline Scene diagnosis for patient & $\begin{array}{r}\text { Number of incorrectly coded } \\
\text { events (\%) }\end{array}$ \\
\hline False alarm & $16(30.8 \%)$ \\
Hanging/overdose/suicide & $9(17.3 \%)$ \\
Alcohol poisoning & $5(9.6 \%)$ \\
Child aged $<11$ with difficulty & $4(7.7 \%)$ \\
breathing & \\
Cancer & $4(7.7 \%)$ \\
Bronchopneumonia/asthma & $4(7.7 \%)$ \\
Neurological problem & $4(7.7 \%)$ \\
Collapse & $2(3.8 \%)$ \\
Vomiting & $2(3.8 \%)$ \\
Other diagnosis (one heart failure, & $2(3.8 \%)$ \\
one pulmonary embolus) & \\
\hline
\end{tabular}

scheme. (The significant reductions in response times were associated with subsequent improvements in survival.) A recent survey of senior staff at UK ambulance services has also revealed a strong preference for the development of First Responder/PAD schemes. ${ }^{21}$ The impact of these First Responder schemes will, however, rely on the accuracy of the dispatch mechanism utilised.

The dispatch mechanism used in the NIPAD trial was a novel internet paging system integrated into the existing AMPDS dispatch computer system that is now deployed by most ambulance services throughout the United Kingdom. The latter is a semi-automated system for taking emergency calls from the public that relies on a standardised format for recording the call information. Clearly, in mounting a response to an emergency call, there is a balance to be struck between the amount of information required to make an accurate provisional diagnosis and the need for the earliest possible dispatch of an appropriate response.

The information recorded relies heavily on the bystander who is making the telephone call to the emergency services. Unsurprisingly, a study by Garza et $a^{22}$ has shown that there is a significant improvement in the positive predictive value (from $45.33 \%$ to $71.67 \%$ ) when the caller is a "first or second party" individual (and therefore present at the scene) as compared with a "third party" caller (who has generally been instructed by another individual to call the emergency services). Garza et $a l^{22}$ reported an overall positive predictive value was $65.0 \%$ (95\% CI $60.0 \%$ to $69.7 \%$ ) and our findings accord well with this (with a local PPV of $63.5 \%$ (95\% CI, $56.1 \%$ to $70.6 \%)$ ).

The AMPDS dispatch mechanism has been previously shown to be more effective than free text descriptions. Heward et $a^{23}$ assessed the use of a previous version of the AMPDS in the London Ambulance Service and demonstrated an improvement in sensitivity for cardiac arrest from 15\% to $50 \%$ after its implementation. The sensitivity found in our study was higher at $68.9 \%$. Our ascertainment procedures were considerably

Table 3 Breakdown of the EMS dispatch codes given to cardiac arrest events

\begin{tabular}{lc}
\hline Dispatch coding given & Number of OHCA (\%) \\
\hline Cardiac/respiratory arrest/death & $106(67.1 \%)$ \\
Unconscious/fainting & $17(10.8 \%)$ \\
Unknown problem - collapse 3rd party & $10(6.3 \%)$ \\
Chest pain & $8(5.1 \%)$ \\
Breathing problems & $7(4.4 \%)$ \\
Stroke & $4(2.5 \%)$ \\
Unknown & $3(1.9 \%)$ \\
Fall & $2(1.3 \%)$ \\
Diabetic problem & $1(0.6 \%)$ \\
\hline
\end{tabular}


Figure 1 Further information for 27 OHCA cases with initial rhythm of VF/NT.

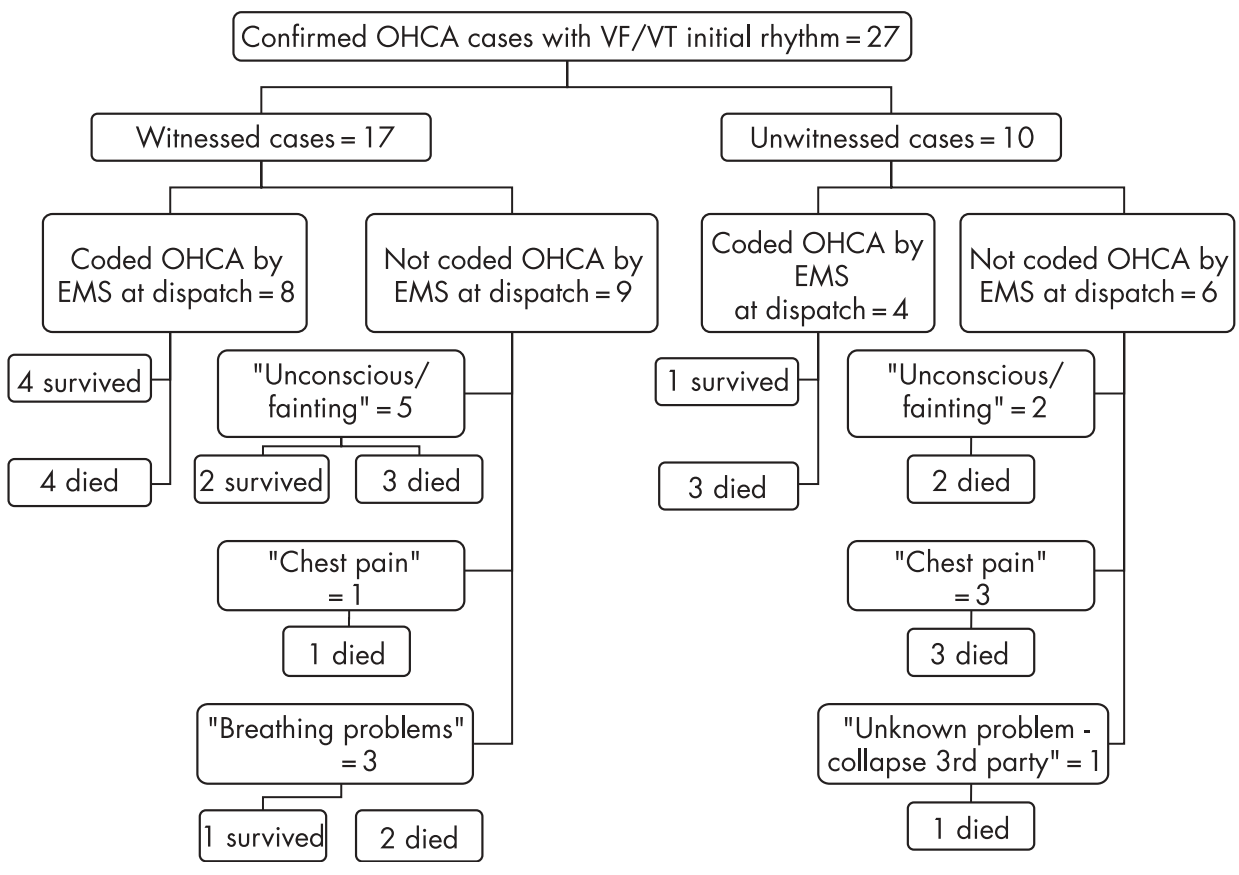

more extensive than either of the previous studies by Heward et $a l^{23}$ or Garza et $a l^{22}$ as we made use of autopsy data and medical records rather than the field diagnoses. We therefore have greater confidence in our estimate.

These findings have substantial significance for the design of a PAD scheme. Volunteers need to be notified quickly of cardiac arrest incidents. For each minute delay in call-to-response time, the survival falls by approximately $10-15 \%$, with survivors rare after 10 minutes. Assigning the wrong dispatch code to OHCA events will reduce the overall benefit of a PAD scheme (table 3 ). The most common incorrect dispatch code described for OHCA was "unconscious/fainting", which is in accordance with the findings of the JRCALC national database. ${ }^{24}$ Including these additional dispatch codes in a PAD scheme would significantly increase the number of calls and would require more extensive training for volunteers.

If the dispatcher were to ask further questions of the caller, some of these diagnoses could eventually be eliminated, but at the cost of an increased delay in response, which could have an adverse effect on survival of those with cardiac arrest.

In the United Kingdom, the Department of Health's target is for responses to a cardiac arrest to be within 8 minutes in $75 \%$ of cases. To achieve this, many ambulance services make use of a variety of responders. The JRCALC database reported that $16 \%$ of all witnessed cardiac arrests in England and Wales were responded to by novel First Responder schemes. In areas where ambulance resources are sparse, a prioritisation system and tactical deployment are essential. ${ }^{25}$ The dispatch mechanism for EMS and PAD first responders thus becomes all the more crucial. The AMPDS system continues to undergo revisions to improve the format.

There are several possible reasons for the high proportion of arrests incorrectly coded. The caller may have given incorrect information, or the dispatcher may have asked insufficiently sensitive questions. A small percentage of patients may experience a change in condition between the time of the first call to the EMS and their arrival.

The difficulty in accurately coding cardiac arrest at the time of dispatch raises questions about how best to ensure that the most rapid responses are targeted to those most likely to benefit. The AMPDS code "Cardiac/Respiratory Arrest/ Death" may be insufficiently sensitive for detecting recent OHCA. This suggests that, to maximise the effectiveness of a First Responder programme, it may be necessary to consider dispatch to a broader range of AMPDS codes. Better public education concerning OHCA recognition may also improve the effectiveness of the current dispatch mechanism. An alternative view is that, in order to improve survival from OHCA, strategies must be put in place by the ambulance service to improve the call-toresponse interval for all category "A" medical emergencies. OHCA remains a common problem and further assessment and improvement of the dispatch mechanism will yield additional gains in survival.

Acknowledgements: We wish to thank the Northern Ireland Ambulance Service for their help and co-operation with this study. The Northern Ireland Public Access Defibrillation Steering group included the authors, Mr J Wright, Dr J Jordan, Ms Y Davison, Mr S Murray, Mr P Ferguson, Ms D Gray, Ms C Bloomfield and Ms M Black.

Funding: This work was funded by the Research and Development Office of the Department of Health, Social Services and Public Safety for Northern Ireland and the British Heart Foundation. The funding agency did not participate in the study design, collection, analysis or writing of the manuscript. Dr KJ Cairns is funded by a RCUK Academic Fellowship.

Competing interests: None declared.

\section{REFERENCES}

1. Engdahl J, Holmberg M, Karlson BW, et al. The epidemiology of out of hospital 'sudden' cardiac arrest. Resuscitation 2002:52:235-45.

2. Pell JP, Corstorphine M, McConnachie A, et al. Post discharge survival following prehospital cardiopulmonary arrest due to cardiac aetiology: temporal trends and impact of changes in clinical management. Eur Heart $J$ 2006;27:406-12.

3. Caffrey SL, Willoughby PJ, Pepe PE, et al. Public use of automated external defibrillators. N Engl J Med 2002;347:1242-7.

4. Myerburg RJ, Fenster J, Velez M, et al. Impact of community-wide police car deployment of automated external defibrillators on survival from out-of-hospital cardiac arrest. Circulation 2002;106:1058-64.

5. Hallstrom AP, Ornato JP, Weisfeldt M, et al. Public Access Defibrillation Trial Investigators. Public Access Defibrillation and survival after out of hospital cardiac arrest. N Engl J Med 2004;351:637-46.

6. Davies CS, Colquhoun M, Graham S, et al. Defibrillators in public places: the introduction of a national scheme for public access defibrillation in England. Resuscitation 2002:52:13-21. 
7. Medical Priority Consultants, Salt Lake City, UT

8. Census, http://www.nisranew.nisra.gov.uk/census/Census20010utput/index.html (accessed 3 Oct 2006).

9. Cummins RO, Chamberlain DA, Abramson NS, et al. Recommended guidelines for uniform reporting of data from out-of-hospital cardiac arrest: The Utstein Style. A statement for health professionals from a task force of the American Heart Association, the European Resuscitation Council, the Heart and Stroke Foundation of Canada, and the Australian Resuscitation Council. Circulation 1991;84:960-75.

10. Jacobs I, Nadkarni V, Bahr J, et al. Cardiac arrest and cardiopulmonary resuscitation outcome reports: update and simplification of the Utstein templates for resuscitation registries. Resuscitation 2004;63:233-49.

11. Chugh SS, Jui J, Gunson K, et al. Current burden of sudden cardiac death: multiple source surveillance versus retrospective death certificate-based review in a large U.S. community. J Am Coll Cardiol 2004:44:1268-75.

12. Chase $\mathbf{D}$, Roderick P, Cooper K, et al. Using simulation to estimate the cost effectiveness of improving ambulance and thrombolysis response times after myocardial infarction. Emerg Med J 2006;23:67-72.

13. Valenzuela TD, Roe DJ, Nichol G, et al. Outcomes of rapid defibrillation by security officers after cardiac arrest in casinos. N Engl J Med 2000;343:1206-9.

14. Pell JP, Sirel JM, Marsden AK, et al. Effect of reducing ambulance response times on deaths from out of hospital arrest: cohort study. BMJ 2001;322:1385-8.

15. Walker A, Sirel JM, Marsden AK, et al. Cost effectiveness and cost utility model of public place defibrillators in improving survival after prehospital cardiopulmonary arrest. BMJ 2003;327:1316-21.
16. Becker L, Eisenberg M, Fahrenbruch C, et al. Public locations of cardiac arrest. Implications for public access defibrillation. Circulation 1998;97:2106-9.

17. Moore MJ, Glover BM, McCann CJ, et al. Demographic and temporal trends in out of hospital sudden cardiac death in Belfast. Heart 2006;92:311-5.

18. Nichol G, Hallstrom AP, Ornato JP, et al. Potential cost effectiveness of Public Access Defibrillation in the United States. Circulation 1998:97:1315-20.

19. Capucci A, Aschieri D, Piepoli MF, et al. Tripling survival from sudden cardiac arrest via early defibrillation without traditional education in cardiopulmonary resuscitation. Circulation 2002;106:1065-70.

20. Cappato R, Curnis A, Marzollo P, et al. Prospective assessment of integrating the existing emergency medical system with automated external defibrillators fully operated by volunteers and laypersons for out-of-hospital cardiac arrest: the Brescia Early Defibrillation Study (BEDS). Eur Heart J 2006;27:553-61.

21. Hassan TB, Barnett DB. Delphi type methodology to develop consensus on the future design of EMS systems in the United Kingdom. Emerg Med J 2002;19:155-9.

22. Garza AG, Gratton MC, Chen JJ, et al. The accuracy of predicting cardiac arrest by emergency medical service dispatchers: The calling party effect. Acad Emerg Med 2003;10:955-60.

23. Heward A, Damiani M, Hartley-Sharpe C. Does the use of the Advanced Medical Priority Dispatch System affect cardiac arrest detection? Emerg Med J 2004;21:115-8.

24. Evans L. JRCALC, Joint Royal Colleges Ambulance Liaison Committee, 2004 National Out of Hospital Cardiac Arrest Project. www.asa.uk.net/content files/files/ NationalOutOfHospitalCardiacArrestAudit2004.pdf (accessed 9 Jan 2008).

25. Department of Health, NHS Modernisation Agency, Best Practice Guidelines on Ambulance Operations Management. www.dh.gov.uk/assetRoot/04/11/23/ 08/04112308.pdf (accessed 3 Oct 2006).

\section{Keep up to date: sign up for our alerting services}

Find out automatically when an article is published on a specific topic or by a particular author. We can also alert you when an article is cited or if an eLetter or correction is published. You can also choose to be alerted when a new issue is published online [and when we post articles Online First]. Check out the New Content Alerts and Citation tracker from the Online tools section on the home page. 